\title{
EXPRESSED EMOTION IN PSYCHIATRIC DISORDERS
}

\author{
Mohapatra Satyakam and Rath NM
}

\begin{abstract}
Expressed emotion (EE) is currently among the most thoroughly investigated psychosocial research constructs in psychiatry. Expressed emotion (EE) is the general reflection of the family's attitude towards the patient as a precursor to relapse in major psychiatric disorders. On the basis of recent research on EE many family intervention programmes have been developed to reduce EE of the family and consequent relapse of illness
\end{abstract}

Key words- Expressed, Emotion, Psychiatric, Disorders

\section{Introduction}

There is vast majority of evidence that the quality of family relationships is closely related to the development, maintenance and treatment response of many psychiatric disorders ${ }^{1}$. The roles of families in the care of people with psychiatric disorders and the ensuing caregiver burden have been increasingly acknowledged in the research literature in the last three decades ${ }^{2,3}$. The chronic burden of caregiving to a patient with psychiatric illness is likely to generate negative emotions. With the advent of deinstitutionalization, caregivers have increasingly assumed greater responsibility for the care of their mentally ill relatives, with the consequent negative caregiving experience a likely cause of stress manifested in heightened Expressed emotion( EE). "Expressed emotion" refers to a global index of particular emotions, attitudes, and behaviors expressed by relatives about a family member diagnosed with psychiatric illness. The concept of EE was introduced in studies done by Brown et $\mathrm{al}^{4}$, where it was shown to have an effect on relapse of schizophrenic patients. In the last 15 years, the EE construct has been extensively studied ${ }^{5,6}$. More than 20 studies, conducted in many countries, have investigated the EE-relapse relationship in patients with schizophrenia. In addition, there is a growing literature concerning the role of EE in unipolar depression ${ }^{7,8}$, bipolar disorder, ,eating disorders ${ }^{10}$ and dementia ${ }^{11}$. The results of these investigations make two things clear. First, rather than being a construct of interest solely with respect to schizophrenia, EE is a more general predictor of poor outcome across a range of conditions. Second, EE is a construct that is modifiable. EE is of interest to researchers and clinicians because it predicts symptom relapse in patients and because family based interventions that seek to reduce EE have had success in decreasing patients' relapse rates ${ }^{12,13}$.

\section{Components of expressed emotion}

George Brown ${ }^{14,15}$ explained five components of EE, which includes critical comments, hostility, emotional overinvolvement, positive remarks (regard), and warmth.

\section{Hostility}

The hostile attitudes of expressed emotion are negative toward the person with the disorder. The family members put blame on this person because of the disorder. The family perceives the person as the one who is in control of the course of the illness. The relatives feel that the family member is being selfish by choosing not to get better since the illness is an internal conflict. The patient is held accountable for any kind of negative incident that occurs within the family and is constantly blamed for the problems of the family. They have a hard time problem solving within the family because the answer to most problems is settled with the disorder being the cause ${ }^{16}$.

\section{Emotional over-involvement}

Emotional over-involvement reflects a set of feelings and behaviour of a family member towards the patient, indicating evidence of over-protectiveness or selfsacrifice, excessive displays of emotion with the use of praise or blame, preconceptions and statements of attitude. Family members who show high emotional involvement tend to be more intrusive. Therefore, 
families with high emotional involvement may believe that patients cannot help themselves and that their problems are due to causes external to them, and thus high involvement will lead to strategies of taking control and doing things for the patients ${ }^{17}$. In addition, patients may feel very anxious and frustrated when interacting with family caregivers with high emotional involvement due to such high intrusiveness and emotional display towards them. On the whole, families with high EE appear to be poorer communicators with their ill relative as they might talk more and listen less effectively ${ }^{18}$. Emotional overinvolvement demonstrates a different side compared to hostile and critical attitudes but is still similar with the negative affect that causes a relapse. The relative becomes so overbearing that the patient can no longer live with this kind of stress from pity, and falls back into their illness as a way cope ${ }^{19}$.

\section{Critical comments}

The critical attitudes of expressed emotion are combinations of hostile and emotional overinvolvement. The family members are more open to view other aspects that contribute to the mental illness and the behavior. These attitudes are more open minded than the previous because they view more than one cause of the disorder. However, there is still negative criticism even though other contributions are viewed and accepted by the relatives. Critical expressed emotion from siblings and parents are the cause of future and increasing problems for the patient. Parents who are critical influence their children to be the same way towards the disorder ${ }^{20}$.

\section{Positive remarks (regard)}

Positive regard comprises of statements that express appreciation or support for patient's behavior and verbal/nonverbal reinforcement by the caregiver.

\section{Warmth}

It is assessed based on kindness, concern, and empathy expressed by the caregiver while talking about the patient. It depends greatly on vocal qualities with smiling being a common accompaniment, which often conveys an empathic attitude by the relative. Warmth is a significant characteristic of the low EE family.

\section{Assessment of expressed emotion}

\section{Camberwell Family Interview (CFI)}

The gold-standard measure of EE is a semi structured interview known as the Camberwell Family Interview $(\mathrm{CFI})^{21}$. The CFI is conducted with the patient's key relative or relatives (typically parents or a spouse) without the patient being present. The CFI is used to make ratings on five scales. These are criticism, hostility, emotional over involvement (EOI), warmth, and positive remarks. Although ratings on five scales are made, practically speaking, the most important EE scales are criticism, hostility, and EOI. It is widely used in clinical population.

\section{The Five Minute Speech Sample (FMSS)}

The Five Minute Speech Sample ${ }^{22}$ requires the family members to talk about their thoughts and feelings about the patient for 5 uninterrupted minutes. The speech is recorded and later coded for the overall level of EE, criticism, and EOI. There is no hostility rating on the FMSS.

\section{Level of Expressed Emotion Scale (LEE)}

The Level of Expressed Emotion Scale ${ }^{23}$ is a 60-item, self report measure that assesses the emotional environment in the patient's most important relationships. Items in the LEE Scale are based on the EE construct, and the four subscales are intrusiveness, emotional response, attitude toward Illness, and tolerance and expectations.

\section{Family Attitude Scale (FAS)}

The Family Attitude $\mathrm{Scale}^{24}$ is a 30 -item self-report measure of EE. It is similar to the LEE in that either relatives or patients may complete it.

\section{Perceived Criticism (PC)}

Of all the alternative measures of EE, the most simple is the perceived criticism measure. This scale recognizes that the most important element of EE is criticism. It consists of only one question, namely "How critical do you consider your relative to be of you?" It is administered as a 10-point Likert-type scale and anchored with the values "not at all critical" and "very critical indeed." This scale takes very less time (1 minute) to administer it. Interviewer can ask patients to rate how critical they think their relatives are of them using this scale.

\section{Expressed Emotion and Relapse}

There is an extensive body of literature that delineates expressed emotion (EE) as a general re? ection of the family's attitude towards the patient as a precursor to relapse $^{25}$. EE probably determines relapse through its effect on emotions and symptom control. A stressvulnerability model of relapse is advanced that incorporates biological factors as well as cycles of mutual influence between symptomatic behaviour, life events, and $\mathrm{EE}^{6}$. 


\section{Schizophrenia}

Majority of studies have demonstrated that a significantly higher number of patients living with highEE relatives relapse than patients living with low EE relatives. Reviewing 26 studies investigating outcome in 1,323 patients, Kavanagh et ${ }^{16}$, found a median first-year relapse rate of 48 percent with high-EE relatives and 21 percent with low; and the Bebbington et $\mathrm{al}^{26}$, aggregate analyses of data from 25 studies gives relapse rates of 50 percent in patients with high-EE families and 21 percent with low. Studies have found hostility to be a more sensitive predictor of relapse $\mathrm{e}^{27,28}$. The Chandigarh study in North India conducted by Leffet $\mathrm{al}^{27}$ found that the only expressed emotion factor to significantly predict the 2year outcome of schizophrenia was hostility.

Study by Ivanovic et $\mathrm{al}^{29}$, showed that critical comment was more frequent in families of patients with paranoid schizophrenia, while emotional over involvement was more frequent in families having a hebephrenic offspring. There was also an inverse relationship between relapse rate and warmth, whether paternal or maternal. This was significant in both subtypes, and indicated that the threshold for the positive effect of warmth was higher for fathers than for mothers.

Recently Rylands et $\mathrm{al}^{30}$, found that high EE stimuli activated brain regions responsible for processing socially aversive information in schizophrenic patients. The emotional valence of the patient's environment signi? cantly impacts upon their well being and illness outcomes.

\section{Mood disorders}

Levels of expressed emotion (EE) in relatives are consistent predictors of relapse among bipolar and other mood disorder patients. Patients with high EE relatives reported higher levels of depression over the 2-year term of follow-up, regardless of treatment condition. High expressed emotion from relatives contributes to the change of state from manic to depression in bipolar disorders $^{31}$. An examination of the dimensions of EE (critical comments and emotional over involvement) indicated that a higher frequency of critical comments predicted higher levels of mania and depression at followup. EE is also a predictor of symptom severity among bipolar patients undergoing pharmacological and psychosocial treatments $^{32}$.

\section{Alcoholism}

Study by O'Farrell et $\mathrm{al}^{33}$, showed that a relapse is more likely to occur with patients that have family members of high expressed emotion more than those that have low expressed emotion. A cycle forms because of the constant criticism of past experiences of drinking which causes a relapse. Family members of high expressed emotion is likely to complain about the drinking before the rehabilitation which causes the start of drinking again. This creates more criticism toward the patient and in addition causes a set back where the person does not care to get better again. This cycle creates problems between the family members and patient that could easily be avoided with less critical comments. Again, the high expressed emotion causes relapse quicker than those with lower expressed emotion because they are less verbally critical of the patient's drinking problem. The fewer negative comments family members make, the longer time there is before a relapse .

\section{Borderline personality disorder}

Research in the area of EE and Axis II disorders is only just beginning. Only one study to date has examined the link between EE and clinical outcome in borderline personality disorder (BPD). Hooley et $\mathrm{al}^{34}$, showed that contrary to prediction, the EE variables of criticism and hostility were not significantly predictive of overall clinical outcome. However, the relatives' level of EOI was significantly predictive of clinical outcome. EE research with BPD patients is still in its infancy, more research is required in this field.

\section{Learning Disabilities}

The environment of high expressed contributes to the progress of the children with a learning disability. They are affected socially because of the stress that they have from their parents about simple abilities that they can not do on their own. The attitude from the parents affect the child and cause more problems. Most parents are emotionally over involved with the child because of the learning disability. The stress to improve becomes a big problem for both the parent and child ${ }^{35}$.

\section{Culture and EE}

EE has been found to be culturally dependent ${ }^{36}$. Research on $\mathrm{EE}$ across different national and ethnic groups has suggested that the sociocultural context may influence the family's emotional climate and levels of $\mathrm{EE}^{37}$. For example, low estimates of $\mathrm{EE}$ have been found particularly in eastern cultural contexts (Japanese: $37 \%{ }^{38}$; East India: $23 \%{ }^{27}$ ), with rural settings showing particularly low levels $\left(0 \%-8 \%\right.$ in India) ${ }^{39,40}$. The highest estimates have been found in European origin cultural contexts (European Canadian:61\% ${ }^{41}$; European American: $67 \%{ }^{42}$ ). Mexican American families have shown rates of high EE at $41 \%{ }^{43 .}$ 
World Health Organization's study on assessing expressed emotion in first-onset schizophrenia in three centres (Chandigarh, Aarhus and London) ${ }^{40}$, reported the lowest ratings on all of the following components : mean number of critical comments; proportion of relatives showing hostility; positive remarks; mean score on warmth; and level of parental over involvement in the Chandigarh sample. Compared with the $54 \%$ of relatives classified as showing high expressed emotion in the two European centres, the Chandigarh sample had only $23 \%$ of relatives classed as showing high expressed emotion. More than a quarter $(29 \%)$ of the Chandigarh sample showed hostility but low criticism. The authors concluded that the Chandigarh relatives commonly express both high criticism and high warmth at the same time. One-year follow-up suggested that the better outcome in cases of schizophrenia in Chandigarh may be related to the high proportion of relatives with low expressed emotion. In a further report, the authors suggest that expression of anger in the form of hostility is relatively unmodified by cultural factors ${ }^{27}$.

\section{Intervention}

The advances in the research on EE in the caregivers of patients with different psychiatric illness in diverse settings have led to the advances in psychosocial intervention strategies with family caregivers. Many family intervention programmes have been developed on the basis of the results of EE research and have components like psycho-education to the patient and caregiver about illness, crisis management, problemsolving skills, clarifying myths and misconceptions, emotional support, and communication skills. Although not all of these programmes are successful, they can reduce the relatives' high-EE score and thus the patients' relapse rates ${ }^{44-46}$

The aim of psycho-education is to reduce EE by educating them and also to reduce the direct contact with high EE caregivers to less than 35 hours per week. Barrowclough et $\mathrm{al}^{47}$ proposed two models of education: Deficit model and interaction model. Deficit model suggests that an inadequate knowledge of information about illness results in negative behavior and disseminating of that knowledge will reduce this behavior and result in more positive attitudes and behaviors toward the patients. Interaction model suggests that people make their own explanations of illness and that information provided by professionals will be understandable, organized, and possibly rejected on the basis of the person's own perceptions and explanations.
Results from several trials of family-based treatment indicate that when family EE levels decrease, patients' relapse rates also fall ${ }^{48}$. From a clinical perspective, these findings are clearly very encouraging.

\section{Conclusion}

The family's EE has been shown to be predictive of outcome in many psychiatric disorders in a variety of cultural settings. Expressed emotion (EE) is currently among the most thoroughly investigated psychosocial research constructs in psychiatry. Future research should stress on the feasibility and efficacy of the strength-based interventions with ongoing psychosocial interventions at individual or group level for the persons and families of different psychiatric disorders to deal with the negative emotional atmosphere of the family.

\section{REFERENCES}

1. Blosch, S. Haffer, J. Harari, E. \&Szmukler, G. The family in clinical Psychiatry. Oxford: oxford university press 1994.

2. Baronet $\mathrm{AM}$ (Factors associated with caregiver burden in mental illness: a critical review of the research literature. ClinPsycholRev(1999):, 19:819-841.

3. Awad AG, Voruganti LN: The burden of schizophrenia on caregivers: a review. PharmacoEconomics,(2008). 26:149-162.

4. Brown, G.W., Monck, E.M., Carstairs, G.M., Wing, J.K., Influence of family life on the course of schizophrenic illness. British Journal of Preventive Social Medicine (1962). 16, 55-68.

5. Hooley JM, Rosen LR, RichtersJEExpressed emotion: toward clarification of a critical construct. Miller Ged.The Behavioral High-Risk Paradigm in Psychopathology New York, NY Springer;(1995), 88- 120

6. Kavanagh DJ : Recent developments in expressed emotion and schizophrenia. Br J Psychiatry:;(1992):160, 601- 620.

7. HooleyJMOrleyJTeasdale JD Levels of expressed emotion and relapse in depressed patients. $\mathrm{Br} \mathrm{J}$ Psychiatry.;(1986), 148642- 647.

8. VaughnCELeff JP The influence of family and social factors in the course of psychiatric illness: a comparison of schizophrenic and depressed neurotic patients. Br J Psychiatry(1976),.;129125137. 
9. MiklowitzDJGoldsteinMJNuechterleinKH Snyder KSMintz JFamily factors and the course of bipolar affective disorder. Arch Gen Psychiatry. (1988):;45225-231.

10. SzmuklerGIEislerIRussellGFMDareC,Anorexia nervosa, parental "expressed emotion," and dropping out of treatment. $\mathrm{Br} \mathrm{J}$ Psychiatry. (1985);147265- 271.

11. VitalianoPPBeckerJRussoJMagaña-Amato Amaiuro RD, Expressed emotion in spouse caregivers of patients with Alzheimer's disease. J ApplSoc Sci.(1989), ;13215- 250.

12. Hogarty, G. E., Anderson, C. M., Reiss, D. J, Family psychoeducation, social skills training, and maintenance chemotherapy in the aftercare treatment of schizophrenia. Archives of General Psychiatry, (1986):43, 633-642.

13. Leff, J., Kuipers, L., Berkowitz, R., Eberlein-Fries, R., \& Sturgeon, D. A controlled trial of social intervention in the families of schizophrenic patients.British Journal of Psychiatry, (1982).141, 121-134.

14. Brown GW. The discovery of expressed emotion: Induction or deduction? In: Leff J, Vaughn C, editors. Expressed emotion in families. New York: Guilford Press;( 1985). p. 7-25.

15. Wearden AJ, Tarrier N, Barrowclough C, Zastowny TR, Rahill AA.,A review of expressed emotion research in health care. ClinPsycholRev (2000);20:633-66.

16. Brewin, C. R., MacCarthy, B. Duda, K., \& Vaughn, C. E. Attribution and expressed emotion in the relatives of the patients with schizophrenia. Journal of Abnormal Psychology(1991),,100,546-554.

17. Barrowclough, C., Haddock, G., Lowens, I. Staff expressed emotion and causal attributions for client problems on a low security unit: An exploratory study.Schizophrenia Bulletin(2001) 27 (3),517-526 .

18. Barrowclough, C., Parle, M., Appraisal, psychological adjustment and expressed emotion in relatives of patients suffering from schizophrenia. British Journal of Psychiatry (1997).171(7), 26-30.

19. Lopez, S. R., Hipke, K. N., Polo, A. J., Jenkins, Ethnicity, expressed emotion, attributions, and course of schizophrenia: Family warmth matters. Journal of Abnormal Psychology, (2004).113, 428-439.
20. Bullock, B. M., Bank, L., \&Buraston, B. Adult sibling expressed emotion and fellow sibling deviance: A new piece of family process puzzle. Journal of Family Psychology(2002).,16, 307- 317.

21. Leff, J. P., \& Vaughn, C. E. Expressed emotion in families. New York: Guilford Press.(1985).

22. Magaña, A. B., Goldstein, J. M., Karno, M., Miklowitz, D. J. A brief method for assessing expressed emotion in relatives of psychiatric patients. Psychiatry Research,(1986) 17, 203-21.

23. Cole, J. D., \&Kazarian, S. S. (1988). The Level of Expressed Emotion Scale: A new measure of expressed emotion. Journal of Clinical Psychology, 44, 392-397.

24. Kavanagh, D. J., O'Halloran, P., Manicavasagar, V., Clark, D., Piatkowska, O., Tennant, C., \& Rosen, A.. The Family Attitude Scale: Reliability and validity of a new scale for measuring the emotional climate of families. Psychiatry Research,(1997) 70, 185-195.

25. Butzlaff,R.L.,Hooley,J.M.,Expressed emotion and psychiatric relapse: a metaanalysis. Archives of General Psychiatry 55(1998)., 547-552 .

26. Bebbington, P., and Kuipers, L; The predictive utility of expressed emotion in schizophrenia: An aggregate analysis. Psychological Medicine, .(1994)24:707-718.

27. Leff J, Wig NN, Ghosh A, et al. Expressed emotion and schizophrenia in North India. III: Influence of relatives' expressed emotion on the course of schizophrenia in Chandigarh. Br J Psychiatry;(1987) 151:166-173

28. MacMillan JF, Gold A, Crow TJ, et al. The Northwick Park study of first episodes of schizophrenia.Expressed emotion and relapse. Br J Psychiatry(1986); 148:133-143.

29. Ivanović M., Z. Vuletić, P. BebbingtonExpressed emotion in the families of patients with schizophrenia and its influence on the course of illness, Social Psychiatry and Psychiatric Epidemiology, (1994), Volume 29, Issue 2, pp 61-65.

30. Rylands,A.J.,McKie,S.,Elliott,R., WilliamDeakin,J.F., Tarrier, N.Afunctional magnetic resonance imaging paradigm of expressed emotion in schizophrenia. The Journal of Nervous and Mental Disease.,(2011). 199 (1), 25-29. 
31. Simoneau, T. L., Miklowitz, D. J., \&Saleem, R. Expressed emotion and interactional patterns in the families of bipolar patients. Journal of Abnormal Psychology,(1998). 107, 497-507.

32. Kim EY, Miklowitz DJ, Journal of Affective Disorders (2004), Volume 82, Issue 3 , Pages 343352.

33. O'Farrell, T. J., Hooley, J., Fals-Stewart, W., \& Cutter, H. S. GExpressed emotion and relapse in alcoholic patients. Journal of Consulting and Clinical Psychology, . (1998). 66, 744-752.

34. Hooley, J. M., \& Hoffman, P. D.. Expressed emotion and clinical outcome in borderline personality disorder. American Journal of Psychiatry,(1999) 156, 1557-1562.

35. Lam, D., Giles, A., \&Lavander, A. Carers' expressed emotion, appraisal of behavioural problems and stress in children attending schools for learning disabilities. Journal of Intellectual Disability Research, (2003).47, 456-463 .

36. Jenkins JH, Karno M. The meaning of expressed emotion: theoretical issues raised by cross-cultural research. Am J Psychiatry 1992;149:9-20.

37. Bhugra, D., \& McKenzie, K. .Expressed emotion across cultures.Advances in Psychiatric Treatment, (2003). 9, 342-348. doi:10.1192/apt.9.5.342.

38. Tanaka, S., Mino, Y., \& Inoue, S. Expressed emotion and the course of schizophrenia in Japan. British Journal of Psychiatry,. (1995) 167, 794-798. doi:10.1192/bjp.167.6.794.

39. Leff, J., Wig, N. N., Bedi, H et alRelatives' expressed emotion and the course of schizophrenia in Chandigarh. British Journal of Psychiatry, (1990). 156, 351-356. doi:10.1192/bjp.156.3.351

40. Wig, N. N., Menon, D. K., Bedi, H et al,. Expressed emotion and schizophrenia in north India: II.Distribution of expressed emotion components among relatives of schizophrenic patients in Aarhus and Chandigarh. British Journal of Psychiatry, (1987) 151, 160-165. doi:10.1192/bjp. 151.2.160.

41. King, S., \& Dixon, M. J.. Expressed emotion and relapse in young schizophrenia outpatients. Schizophrenia Bulletin, (1999)25, 377-386.

42. Vaughn, C., \&Leff, J.The measurement of expressed emotion in the families of psychiatric patients. British Journal of Social and Clinical Psychology,(1976) 15, 157-165 ; and British: 45\%.
43. Karno, M., Jenkins, J. H., de la Selva, A et al, Expressed emotion and schizophrenic outcome among Mexican-American families. Journal of Nervous and Mental Disorders, (1987).175, 143-151.

44. Barbato A. \& D'Avanzo B. Family interventions in schizophrenia and related disorders: a critical review of clinical trials. Acta Psychiatrica Scandinavica (2000). 102, 81-97.

45. Dixon L., Adams C. \&Lucksted A. Update on family psychoeducation for schizophrenia. Schizophrenia Bulletin (2000).26(1), 5-20.

46. Pilling S., Bebbington P., Kuipers $\mathrm{E}$ et al, Psychological treatments in schizophrenia: I. Meta-analysis of family intervention and cognitive behaviour therapy. Psychological Medicine (2002).32(5), 763-782.

47. Barrowclough C, Johnston M, Tarrier NAttributions, expressed emotion, and patient relapse: An attributional model of relatives' response to schizophrenia illness. Behav Ther (1994).;25:67-88.

48. Lam DH Psychosocial family intervention in schizophrenia: a review of empirical studies. Psychol,(1991), Med.;21423-441.

\section{Authors:}

\section{Dr. Satyakam Mohapatra, MD}

Senior Resident

Mental Health Institute

S. C. B. Medical College

Cuttack, Odisha, 753007

2. Dr. N. M. Rath, MD

Director and Superintendent

Mental Healthinstitute

S. C. B. Medical College

Cuttack, Odisha, 753007

\section{CORESSPONDINGAUTHOR}

Dr. Satyakam Mohapatra, MD

Senior Resident

Mental Health Institute

S. C. B. Medical College

Cuttack, Odisha, 753007

EMAIL ID-satyakgmu@gmail.com

Mobile No- 08895293997 